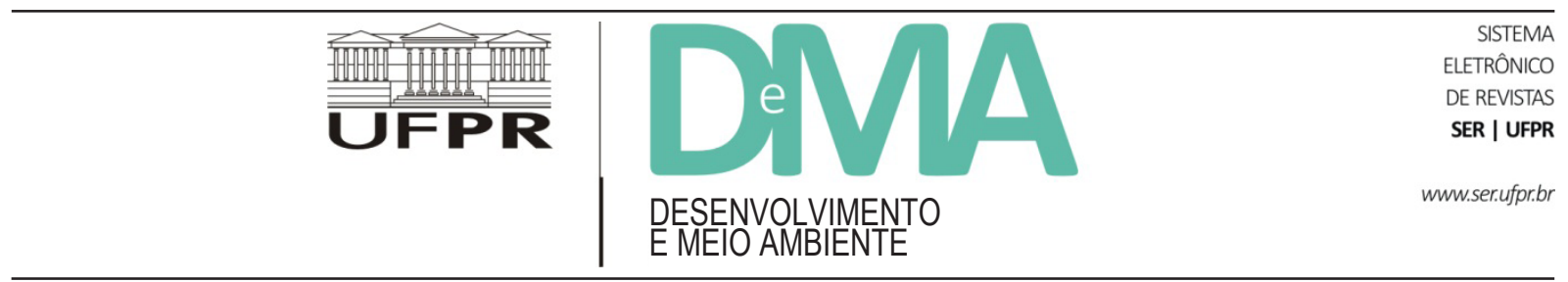

\title{
Energia, água e relações entre Ciência, Tecnologia, Sociedade e Ambiente no ensino de ciências: interações discursivas e possibilidades formativas
}

\section{Energy, Water and Relations among Science, Technology, Society and Environment in Science Teaching: Discursive Interactions and Formative Possibilities}

\author{
Ana Maria TEIXEIRA ${ }^{1,2}$, Noemi SUTIL ${ }^{2 *}$ \\ ${ }^{1}$ Secretaria de Estado da Educação do Paraná, Curitiba, PR, Brasil \\ ${ }^{2}$ Programa de Pós-Graduação em Formação Científica, Educacional e Tecnológica (FCET), Universidade Tecnológica Federal do Paraná \\ (UTFPR), Curitiba, PR, Brasil. \\ *E-mail de contato: noemisutil@hotmail.com
}

Artigo recebido em 29 de fevereiro de 2016, versão final aceita em 28 de abril de 2016.

RESUMO: Energia e água podem ser relacionadas no escopo controverso dos interesses, negociações e decisões concernentes à geração de energia elétrica em hidrelétricas. Nesse contexto, o contato de estudantes com tais temas se apresenta relevante para viabilizar condições para o desenvolvimento crítico e reflexivo dos mesmos, em relação a temas controversos. Dessa forma, neste trabalho se analisa o envolvimento argumentativo de estudantes em atividades educacionais que abordam dimensões científicas, políticas, econômicas, sociais e ambientais, no processo de geração de energia elétrica. Tais atividades envolvem controvérsias em torno da construção da usina hidrelétrica de Belo Monte, no Rio Xingu, no Estado do Pará. Esta proposta possui fundamentos teóricos na Teoria do Agir Comunicativo de Jürgen Habermas, em proposição de formação para o entendimento e acordo, em argumentação livre de coerção, articulando aspectos de inteligibilidade, nos âmbitos objetivos, sociais e subjetivos. Os sujeitos participantes foram alunos de $9^{\circ}$ ano na disciplina de Ciências em um colégio estadual paranaense. Os dados foram constituídos por meio de gravações em áudio e vídeo e registros em diário de campo. As interações discursivas foram analisadas por meio de Análise de Conteúdo e estudo de textos e discursos argumentativos. Entre os resultados, podem ser destacados: o envolvimento dos sujeitos em problematização e proposições de alternativas para construções conjuntas; e o reconhecimento para o enfrentamento de invasões sistêmicas no mundo da vida. Entretanto, podem ser explicitadas limitações na participação dos estudantes. Os processos argumentativos dos estudantes, explicitados neste trabalho, apontam para a possibilidade de formação para o entendimento e acordo na educação em ciências.

Palavras-chave: energia; água; ciência, tecnologia, sociedade e ambiente; argumentação; ensino de ciências. 
ABSTRACT: Energy and water can be related in the controversial field of interests, negotiations and decision making concerning the electrical energy generation process in hydroelectric dams. In this context, the contact of students with these themes is relevant to enable conditions for their critical and reflective development, in relation to controversial issues. In this sense, in this work, the argumentative involvement of students, in educational activities with the approach of dimensions of science, politics, economics, social and environmental is analyzed, in the process of electrical energy generation. These activities involve controversies related to the construction of the hydroelectric dam of Belo Monte, in Xingu River, in the state of Pará. This proposal has its fundamentals in the assumptions of the communicative action theory by Jürgen Habermas, in the proposition of formation for understanding and agreement, in argumentation free of coercion, with the articulation of aspects in the intelligibility, objective, social and subjective domains. The subjects in this research were Sciences students in $9^{\circ}$ grade in a public school in the state of Paraná. Data was constituted of audio and video records and written records in a field diary. The discursive interactions were analyzed considering Content Analysis and the study of argumentative texts and discourses. Among the results, it can be highlighted: the involvement of the subjects in the problem-posing and propositions of alternatives aiming joint constructions; the recognition aiming confront of systemic invasions in the lifeworld. However, limitations in the participation of the students can be explicited. The argumentative processes of students, presented in this work, point to the possibility of formation for understanding and agreement in science teaching.

Keywords: Energy; water; science, technology, society and environment; argumentation; science teaching.

\section{Introdução}

No escopo das controvérsias sobre objetivos e ações nos processos educativos, podem ser problematizadas concepções e propostas de ensino e aprendizagem fundamentadas na compartimentalização disciplinar. Nessa perspectiva, o ensino de ciências remete a fragmentos, descontextualizados e insuficientes para a formação de um sujeito crítico e criativo, envolvido em construções conjuntas democráticas.

Como nossa educação nos ensinou a separar, compartimentar, isolar, e não a unir os conhecimentos, o conjunto deles constitui um quebra-cabeças ininteligível. [...] Os grandes problemas humanos desaparecem em benefício dos problemas técnicos particulares (Morin, 2000, p. 42-43).

O ensino contemporâneo de ciências ainda é, na maioria das situações, disciplinar e restrito ao domínio cognitivo. É, portanto, muitas vezes, estéril, carente de relevância social, e com base em livros didáticos que apresentam teorias puras e claras, regras da natureza e soluções corretas para os problemas. Tal ensino busca ainda a capacidade de resolução de exercícios, principalmente aplicação de algoritmos já conhecidos, mas não habilidades em solucionar problemas. As soluções para os exercícios exigem conhecimento de fatos e formas, ao invés de raciocínio e utilização de juízos de valor. Esse ensino de ciências busca o conhecimento e sua compreensão, mas raramente a análise, a síntese e a avaliação. Há o incentivo de aspectos formais para solucionar problemas técnicos e desencoraja o raciocínio de qualidade e criatividade. $\mathrm{O}$ ensino de ciências propaga, assim, a convicção ingênua de que a ciência e a tecnologia podem estabelecer tanto o que "podemos fazer" como o que "devemos fazer". (Zoller, 1992).

Em contraposição a essa tendência de fragmentação, podem ser destacadas propostas educacionais envolvendo as relações entre Ciência, Tecnologia, Sociedade e Ambiente (CTSA). Nesse 
sentido, Ratcliffe \& Grace (2003) defendem uma abordagem educacional em que os alunos reconheçam os cientistas na determinação de política social. Eles, também, ressaltam que os discentes devem reconhecer a natureza do conhecimento científico, as razões pelas quais os especialistas discordam, os problemas que ocorrem quando isto acontece e a maneira como os conhecimentos científicos são retratados nos meios de comunicação. Destacam que estes aspectos levados em consideração em uma sala de aula de ciências contribuem para uma educação científica para a cidadania que não se refere apenas à disponibilização de conhecimentos e à compreensão de conceitos científicos. A formação em ciências, portanto, envolve o acesso ao conhecimento detalhado e complexo da ciência para finalidades próprias, com a análise de fontes de informação, considerando riscos e benefícios relacionados a questões científicas e tecnológicas; remete, ainda, à tomada de decisão em questões controversas contemporâneas. Tais autores ainda ressaltam que os valores, atitudes e conhecimentos científicos estão interligados ao se fazer julgamentos e defendem a análise, em contraposição a ignorar ou compartimentar tais relações.

Nesse cenário de proposições para o ensino de ciências com o estabelecimento de relações entre diversas áreas de conhecimentos, problematização das relações entre ciência, tecnologia, sociedade e ambiente e apresentação de alternativas para essas situações controversas, pode-se associar a Teoria do Agir Comunicativo de Jürgen Habermas. A educação em ciências, nessa proposta, refere-se à formação para o entendimento e acordo, com a problematização e a construção conjunta democrática dos âmbitos objetivo, social e subjetivo, em argumentação; envolve ainda a composição de panorama linguístico, de inteligibilidade.

Entre as possibilidades de abordagem das relações entre ciência, tecnologia, sociedade e ambiente, podem ser situados os temas água e energia. No que concerne à geração de energia elétrica em hidrelétricas, destacam-se conflitos envolvendo aspectos de caráter científico-tecnológico, políticos, econômicos e humanitários. Esses processos conflituosos remetem à necessidade de agir comunicativo.

A construção de usinas hidrelétricas envolve diversos sujeitos, perspectivas e interesses. De um lado estão os empreendedores, com projetos lucrativos, fundamentalmente econômicos, buscando ocultar conflitos. De outro lado, a população atingida, evidenciando conflitos, reclamando direitos violados, com critérios fundamentalmente ambientais, sociais e humanísticos (Rezende, 2002).

Dessa forma, apresenta-se neste trabalho a discussão de possibilidades formativas concernentes a atividades educacionais, considerando pressupostos da Teoria do Agir Comunicativo, desenvolvidas com alunos de $9^{\circ}$ ano de Ensino Fundamental, na disciplina de Ciências, com abordagem de relação entre água e energia, particularmente as controvérsias em torno da construção da usina hidrelétrica de Belo Monte, no Rio Xingu, no Estado do Pará.

Este trabalho se encontra organizado com a apresentação de pressupostos da Teoria do Agir Comunicativo. A seguir, tais pressupostos são articulados à abordagem das relações entre ciência, tecnologia, sociedade e ambiente. São apresentadas características gerais da pesquisa e a estruturação das atividades educacionais. A análise e a discussão de dados se referem a quatro episódios envolvendo argumentação entre discentes. 


\section{Teoria do Agir Comunicativo}

\subsection{Entendimento e acordo, argumentação e âmbitos}

Formação, em perspectiva habermasiana, remete a entendimento e a acordo, relaciona-se com o envolvimento em problematização e construção conjunta.

"Entendimento" (Verständigung) significa a união dos participantes da comunicação sobre a validade de uma exteriorização; ao passo que "acordo" ou "consenso" (Einverständnis) tem a ver com o reconhecimento intersubjetivo da pretensão de validade que o falante une a uma exteriorização (Habermas, 2012b, p. 221, grifos do autor).

Em perspectiva habermasiana, a linguagem é concebida como meio de entendimento e acordo e a formação do sujeito está relacionada à argumentação. Esta formação abrange três campos específicos: cultura, sociedade e personalidade; a ação comunicativa é baseada em processo de cooperação em que os participantes fazem referências aos âmbitos objetivo, social e subjetivo. A esses três domínios, agrega-se, ainda, âmbito explicativo, relacionado à possibilidade de compreensão das sentenças emitidas, considerando aspectos de estruturação da linguagem e quadros de significados (Habermas, 2002; 2012a; 2012b).

A cultura constitui a reserva do conhecimento, na qual os participantes da comunicação procuram se entender; refere-se ao âmbito objetivo. A sociedade se baseia em leis, por meio das quais os participantes da comunicação se regulam em grupos sociais na defesa da solidariedade; relaciona-se com o âmbito social. Em termos de personalidade, o sujeito preserva sua identidade por meio do falar e do agir; associa-se ao âmbito subjetivo. Nos atos de falas consensuais, pressupõe-se o reconhecimento pelos sujeitos participantes de quatro pretensões de validade em relação ao conteúdo expresso, seja verdadeiro (âmbito objetivo), seja correto em relação às normas vigentes (âmbito social), seja sincero $\mathrm{e}$ os participantes possam confiar (âmbito subjetivo), seja inteligível para que o ouvinte possa entender (âmbito explicativo) (Habermas, 2002).

Problematização e construção conjunta podem ser associadas a processos nesses âmbitos. No âmbito objetivo, o discurso teórico constitui o processo pelo qual as experiências negativas podem ser elaboradas de modo produtivo e pretensões de validade controversas podem ser transformadas em proposições. A pessoa é considerada racional por agir de maneira eficiente e exterioriza opiniões fundamentadas, aprende a partir dos maus resultados, a partir da refutação de hipóteses e do fracasso de algumas intervenções. No âmbito social, considera-se racional a pessoa capaz de justificar suas ações por meio das normas existentes em determinado contexto em situações de ações. No caso de conflitos normativos, ela aprende quando age de forma razoável e se porta com imparcialidade, superando o conflito de forma consensual. O discurso prático é a forma de argumentação que permite tematizar pretensões às normas estabelecidas, constitui o processo que possibilita avaliar se determinada norma pode ser justificada de forma imparcial. No âmbito subjetivo, em crítica terapêutica, também se considera racional o comportamento de uma pessoa que esteja determinada a se libertar de ilusões baseadas em autoenganos. Isso se refere a exteriorizações de desejos, sentimentos, estados de espírito com pretensão de veracidade. A pessoa aprende quando assume uma postura de reflexão diante das próprias exteriorizações expressivas. No discurso explicativo, considera-se racional uma pes- 
soa com disposição positiva para o entendimento, diante da dificuldade na comunicação; ela aprende quando reage de forma reflexiva sobre a linguagem. Trata-se da compreensão das expressões simbólicas. Trata-se também da explicação do significado das exteriorizações, uma tarefa hermenêutica. O discurso explicativo é o modo de argumentação em que a compreensão, a boa formulação ou a regularidade das expressões simbólicas se tornam tema de discussão controversa (Habermas, 2012a).

Esses âmbitos, discursos e crítica, e pretensões de validade podem ser considerados em processo de problematização e construção conjunta em educação em ciências.

\subsection{Mundo da vida e sistema}

Jürgen Habermas concebe a sociedade em termos de mundo da vida e sistema. O mundo da vida é "o contexto, por excelência, da comunicação linguística, onde ocorre a práxis comunicativa do dia a dia, isto é, o processo de comunicação voltado ao entendimento e à busca do consenso através da fala" (Mühl, 2003, p. 205). O mundo da vida é uma fonte cultural de convicções e saberes, um local onde se originam os processos de entendimento. O sistema se constitui na coordenação da ação por meios como dinheiro e poder; envolve Mercado e Estado, com atribuição de papéis de consumidores e cidadãos; esses meios que coordenam as ações procuram reduzir o risco de desentendimento e as demandas por comunicação.

O sistema pode invadir o mundo da vida, colonização do mundo da vida, minimizando os riscos de desentendimento e a demanda por comunicação, em detrimento do aspecto comunicativo. Essa invasão estabelece dinheiro e poder na coordenação das ações, reduzindo-as ao âmbito estratégico. As consequências dessa imposição são a instrumentalização do mundo da vida, a restrição do agir comunicativo para um agir estratégico. A educação como parte integrante do mundo da vida também fica condicionada a estas consequências (Mühl, 2003).

Aspectos concernentes a essa invasão do sistema no mundo da vida, que perpassam as relações entre ciência, tecnologia, sociedade e ambiente, podem ser problematizados e constituir elementos de construção conjunta na educação em ciências, com a instauração de discurso teórico e prático e crítica terapêutica.

\section{Relações entre Ciência, Tecnologia, Sociedade e Ambiente (CTSA) no ensino de ciências}

Habermas (1968), considerando proposições de Herbert Marcuse, destaca que na sociedade capitalista a racionalidade empregada na ciência e na técnica constitui uma forma determinada de dominação política oculta; a ciência e a técnica impõem uma dominação sobre a natureza e sobre a sociedade. Contudo, o indivíduo não reconhece a institucionalização de uma dominação política por meio da ciência e da técnica. A racionalidade da técnica e da ciência constitui em si mesma uma ideologia. Na ciência e na técnica se projeta uma sociedade, na qual interesses dominantes decidem o que fazer com os indivíduos e com as coisas. Dessa forma, não se pode conceber uma emancipação do indivíduo sem que ocorra uma revolução abrangendo ciência e técnica.

$\mathrm{Na}$ perspectiva habermasiana, a técnica e a ciência se configuram como uma nova forma de dominação, na medida em que não há preocupação em relação aos fatores históricos, às controvérsias e 
às questões de relações entre poder, conhecimentos e valores; a ciência se associa à coleta e à classificação de fatos. Este contexto de construir a ciência está vinculado ao pensamento positivista, que se tipifica por ser uma forma de perceber a ciência desligada de compromissos éticos, encerrando os fatos como dados objetivos, garantindo-se o acesso à verdade pela neutralidade do método (Habermas, 1968; Mühl, 2003).

Para Paulo Freire (1987), a ciência e a tecnologia são forças que podem manter a ordem opressora, podem servir para manipular e esmagar. Os opressores delas se apropriam como instrumentos para finalidades próprias. A terra, os bens, a produção, o próprio homem, tudo se reduz a objeto de comando dos opressores. Uma concepção materialista da existência se impõe, o dinheiro é a medida e o objetivo principal é o lucro.

Nesse sentido, pode-se associar a abordagem das relações entre ciência, tecnologia, sociedade e ambiente no ensino de ciências, para viabilização de espaços para problematização desses aspectos ideológicos e opressores, associados aos domínios científico e tecnológico, e para construção conjunta. Propostas educacionais envolvendo relações CTSA não se restringem à resolução de exercícios pelos estudantes e demandam a viabilização de condições para o desenvolvimento de pensamento crítico e reflexivo. Essa abordagem requer:

[...] olhar para um problema e suas implicações e reconhecê-lo como um problema, enxergar seu núcleo factual de conhecimentos e conceitos envolvidos, e apreciar a significância e o significado de resoluções alternativas. Isso implica resolução de problemas (não resolução de exercícios) para reconhecer/selecionar a informação relevante, avaliar a confiabilidade das fontes usadas e seu grau de preconceito, e para elaborar/planejar procedimentos/estratégias apropriados para enfrentamento dos problemas. Isso envolve esclarecimento de estruturas de valor/posições e realização de julgamentos de valor (e defesa), realização de escolhas racionais entre alternativas disponíveis, e geração de novas opções. E, finalmente, isso significa ação sobre decisão, e tomada de responsabilidade sobre os efeitos (Zoller, 1992, p. 87, tradução nossa).

Ainda de acordo com Zoller (1992), estudantes envolvidos em discussões de relações CTSA têm possibilidades de propor alternativas a grandes problemas, tomar posições com base em suas análises cognitivas e de valores e agir conforme a posição defendida. A educação associada às relações CTSA se configura como política. Destina-se ao envolvimento ativo e responsável do estudante cidadão na ação. Destina-se deliberadamente a possibilitar aos alunos passarem do automatismo inconsciente para a percepção consciente de decisões e comportamentos. Decisões carregadas de valores podem ser feitas. Não tomar nenhuma decisão é decidir.

Em educação científica sob a perspectiva da Teoria do Agir Comunicativo, com abordagem das relações CTSA: os objetivos educacionais remetem à formação para o entendimento e para o acordo; os conteúdos perpassam essas controvérsias associadas à ciência e tecnologia nos contextos vivenciais; as atividades educacionais podem envolver situações de problematização e de elaboração, expressão e análise de argumentos para construções conjuntas em âmbitos objetivo, social, subjetivo e explicativo concernentes a essas controvérsias. Esses processos implicam a instauração de discursos explicativo, teórico e prático e crítica terapêutica, remetendo à explicitação de pretensões de validade de inteligibilidade, verdade, acerto e veracidade. Tais pressupostos constituem fundamentos das atividades educacionais desenvolvidas e analisadas neste trabalho. 


\section{As controvérsias da hidreletricidade}

O documentário "Belo Monte, o anúncio de uma guerra" retrata as angústias de uma população ribeirinha que será atingida pela barragem da usina hidrelétrica de Belo Monte e os indígenas que terão o rio, relacionado à sua sobrevivência, impactado pela redução da água e de peixes. O documentário evidencia as perdas simbólicas que esta população terá por causa da construção da usina (Belo Monte, 2012).

Para Ferreira et al. (2014), perdas simbólicas dos atingidos por barragens se referem aos sentimentos e às relações dos indivíduos com o meio ambiente onde vivem. Em seus estudos, tais autores constatam que as normas técnicas de indenização das populações atingidas por barragem ignoram as relações dos ribeirinhos com seu ambiente de construção cultural; essas normas não consideram as perdas por estes sujeitos da utilização de recursos como a água, os peixes e a paisagem. As diretrizes do setor elétrico brasileiro utilizam uma visão objetiva dos impedimentos relacionados à construção de usinas hidrelétricas, incluindo o modo de vida dos ribeirinhos e os elementos simbólicos destas pessoas. Na visão do empreendedor do setor elétrico, as casas e as terras são um bem pagável por meio de um negócio imobiliário. Contudo, para os moradores dessas comunidades, não há preço que pague os sentimentos, as relações dos indivíduos com o meio onde vivem. Para pequenos produtores, o cultivo em vazante próxima aos rios e nas ilhas constitui importante meio para adquirir alimento para o sustento das famílias, para a geração de renda. No momento em que estas pessoas são reassentadas, todos estes elementos não são levados em consideração.

As populações ribeirinhas são desconsideradas diante do processo de formação do reservatório da usina. Estas populações sofrem perdas irreversíveis em suas condições de produção e reprodução social. Elas têm destruídos seus projetos de vida, não têm asseguradas condições de reprodução, tal qual eram antes da implantação do empreendimento (Bermann, 2007).

O documentário "Belo Monte, o anúncio de uma guerra" também faz destaques aos problemas ambientais que a construção da usina hidrelétrica de Belo Monte trará para as áreas atingidas. Nesse documentário, Renata Pinheiro, assessora técnica do Movimento Xingu Vivo, em seu depoimento, expressa que as pessoas que residem na Volta Grande do Xingu possam perder os peixes. Ela explicita que a floresta pode secar, pois a fauna e a flora dependem do fenômeno natural de inundação e seca; as populações que ali vivem precisam destes recursos naturais e, para ela, estas comunidades foram ignoradas, como se não existissem (Belo Monte, 2012).

Frequentemente no Brasil e no cenário internacional, os empreendimentos hidrelétricos se mostram insustentáveis. Problemas de insustentabilidade são estabelecidos a partir de critérios que dimensionam domínios físico-químico-biológicos. Destacam-se vários problemas nesse sentido, tais como: alteração do regime hidrológico, comprometimento da qualidade das águas, assoreamento, emissão de gases do efeito estufa, problemas de saúde, entre outros. Mas por outro lado, comparada à geração de energia elétrica a partir de combustíveis fósseis, a hidreletricidade é percebida como uma fonte de energia limpa, renovável e barata. Sugere-se em situações controversas a necessidade de estabelecer consensos em condições relacionadas à questão energética. Ao construir consensos, são reconhecidos interesses divergentes que precisam ser levados em consideração nos processos de negociação (Bermann, 2007). 
Por isso, ao levar uma temática controversa como a hidreletricidade para um ambiente educacional, pode-se relacioná-la aos pressupostos da Teoria do Agir Comunicativo, pois, por meio de argumentos, os estudantes poderão se posicionar diante da temática. Eles poderão elaborar seus pontos de vista, analisar aspectos positivos e negativos e construir consensos. Uma proposta educacional desenvolvida nesses fundamentos pode oferecer oportunidades de uma formação para o entendimento e acordo.

\section{Procedimentos metodológicos}

Este trabalho envolve uma pesquisa qualitativa e participante (Flick, 2009), fundamentada na Teoria do Agir Comunicativo (Habermas, 2002; 2012a; 2012b). Os sujeitos envolvidos foram 44 alunos do $9^{\circ}$ ano, na disciplina de Ciências, com idade entre 14 e 19 anos de um colégio público paranaense. Os dados foram constituídos por meio de gravação em áudio e vídeo das discussões estabelecidas em sala de aula e de registros escritos em diário de campo. Os dados foram analisados por meio de Análise de Conteúdo (Bardin, 2011) e estudo de textos e discursos argumentativos (Van Eemeren \& Grootendorst, 2004).

Para o desenvolvimento da pesquisa, foram elaboradas atividades educacionais envolvendo temas controversos na temática geração de energia elétrica, com duas turmas de $9^{\circ}$ ano (C e D) durante as aulas de Ciências, em 2015. Essas atividades educacionais foram organizadas de forma a contemplar os momentos pedagógicos propostos por Delizoicov et al. (2002): problematização inicial, organização do conhecimento e aplicação do conhecimento.

As atividades educacionais abordavam as controvérsias concernentes à construção da Usina de Belo Monte, no Rio Xingu, no Estado do Pará. Após anos de estudo, o Governo Federal iniciou em 2011 a construção desta usina e, desde então, suas obras foram interrompidas mais de 20 vezes. A obra envolve questões ambientais de destruição da floresta, alteração de ecossistemas e redução da vazão do Rio Xingu que impactam fortemente a sobrevivência de tribos indígenas que vivem nesta área. Muitas obras que deveriam ser feitas para a população, para compensar as perdas, não foram realizadas. Em contexto de problemas de comunicação, os conflitos acabam sendo judicializados e isto expõe indígenas, ribeirinhos e agricultores a uma situação de vulnerabilidade, colocando em risco a integridade sociocultural e física das populações atingidas.

Na Tabela 1, a seguir, é apresentado o detalhamento das atividades educacionais desenvolvidas.

As atividades educacionais permitiram aos alunos a aproximação a um caso distante em termos de localização territorial, mas, ao mesmo tempo, próximo pelo fato de serem consumidores de energia elétrica. O contato dos alunos com a temática aconteceu por meio de documentário e reportagens considerados, em termos de preparação, adequados ao nível de ensino dos estudantes. A intenção foi fornecer informações, fatos e elementos acerca do caso com a finalidade de viabilizar a tomada de posição contra ou a favor da construção da usina, com proposições de alternativas a problemas envolvendo questões sociais e ambientais relacionadas ao desenvolvimento científico e tecnológico.

\section{Análise e discussão dos dados}

Para a identificação de possibilidades formativas no processo desenvolvido, considerando as interações discursivas dos sujeitos envolvidos, 
TABELA 1 - Detalhamento de atividades educacionais.

\begin{tabular}{|c|c|}
\hline Atividades & Assistir e discutir o documentário "Belo Monte, o anúncio de uma guerra" \\
\hline Carga horária & $\begin{array}{l}9^{\circ} \mathrm{C}: 9 \text { aulas } \\
9^{\circ} \mathrm{D}: 7 \text { aulas }\end{array}$ \\
\hline Material de apoio & $\begin{array}{l}\text { Televisão; } \\
\text { Documentário “Belo Monte, o anúncio de uma guerra”, ano de produção 2012, país de origem Brasil, } \\
\text { duração de } 104 \text { minutos, produção André D’Elia. Disponível em: < https://vimeo.com/cinedelia>. } \\
\text { Acesso em: } 29 \text { fev. } 2016 \text {. }\end{array}$ \\
\hline
\end{tabular}

FONTE: Elaboração própria.

foram estabelecidos os seguintes eixos de análise: 1) envolvimento em problematização e construção conjunta; 2) reconhecimento para enfrentamento de invasões sistêmicas no mundo da vida, considerando relações entre ciência, tecnologia, sociedade e ambiente. A Tabela 2, a seguir, apresenta aspectos da composição desses eixos de análise. Na apre- sentação de exemplares associados a tais eixos, os turnos (com as expressões dos sujeitos) são representados pela letra $\mathrm{T}$, seguida de número (exemplo: T1); os estudantes são identificados pela letra B, seguida de número (exemplo: B1); e a docente se encontra representada pela letra $\mathrm{P}$.

TABELA 2 - Composição eixo de análise: envolvimento em problematização e construção conjunta.

\begin{tabular}{|c|c|c|c|c|}
\hline Discurso & $\begin{array}{l}\text { Âmbito- } \\
\text {-Mundo }\end{array}$ & $\begin{array}{l}\text { Pretensões de } \\
\text { validade }\end{array}$ & Atitudes básicas & Aspectos de problematização e construção conjunta \\
\hline Teórico & Objetivo & Verdade & Objetiva & $\begin{array}{l}\text { Questionamento/Explicitação de concepções, de saberes e de } \\
\text { conhecimentos estabilizados. }\end{array}$ \\
\hline Prático & Social & $\begin{array}{l}\text { Acerto/ } \\
\text { Adequação }\end{array}$ & $\begin{array}{l}\text { Conforme as } \\
\text { normas }\end{array}$ & Questionamento/Explicitação de normas e direitos. \\
\hline $\begin{array}{l}\text { Crítica } \\
\text { terapêutica }\end{array}$ & Subjetivo & Sinceridade & Expressiva & Questionamento/Explicitação de atitudes e sentimentos \\
\hline Explicativo & $\begin{array}{l}\text { Mundo da } \\
\text { vida }\end{array}$ & Inteligibilidade & & $\begin{array}{l}\text { Questionamento/Explicitação de estruturas linguísticas e } \\
\text { significados. }\end{array}$ \\
\hline
\end{tabular}

FONTE: Elaboração própria. 
Após assistirem ao documentário "Belo Monte: o anúncio de uma guerra", a docente introduz o diálogo retomando trechos do filme, com a finalidade de verificar as impressões dos alunos sobre as questões abordadas no documentário e constatar as opiniões e proposições desses discentes, considerando os diversos depoimentos de sujeitos que se manifestaram contra ou a favor da construção da Usina de Belo Monte. A seguir, são apresentadas análises de interações discursivas em quatro episódios.

\subsection{Episódio 1}

Este episódio corresponde ao reconhecimento de situação envolvendo água e geração de energia elétrica e busca pelo estabelecimento de discurso teórico.
Este momento se refere à busca de instauração de discurso teórico com o questionamento e a explicitação de concepções, de saberes e de conhecimentos estabilizados; perpassa, também, a busca pelo estabelecimento de discurso explicativo, considerando os diversos significados e conceitos que poderiam ser desconhecidos aos alunos.

Neste episódio, é possível perceber a professora iniciando a conversação, recordando a informação sobre a redução da vazante do Rio Xingu, como consequência das ações para a construção da usina. Neste caso, o aluno B8 identifica o represamento da água como a causa da vazante diminuir. A professora lança uma pretensão de verdade em relação à afirmação do aluno B8, quando pede uma confirmação ou uma complementação em relação a sua resposta. No diálogo, nenhum aluno demonstrou lembrar que o desvio do rio para um canal, com a finalidade de construir o reservatório da usina,

T1. P: Pessoal, sobre of filme, Rio Xingu, mostrava lá que tinha a Volta Grande do Xingu, vai diminuir a vazante da água. Por que vai diminuir a água do rio?

T2. B2: Porqueeee, porqueee...

T3. B19: Porqueee...

T4. P: O que vai ser feito com a água?

T5. B8: Eles iam represar a água em cima e embaixo os índios iam ficar sem água.

T6. P: A represa faz com que diminua a água na parte debaixo do rio, então? Mas tem mais uma causa que faz com que diminua a vazante do rio Xingu, eles vão desviar o rio, não lembram desta informação?

T7. Alunos: nããão!

T8. P: Táh! A principal causa da vazante do rio diminuir seria um canal de $20 \mathrm{~km}$ a ser construído que levaria a água para o reservatório da usina. Quais as consequências disso? Da água diminuir?

T9. B8: I ficar sem alimento, sem os peixes.

T10. P: Os peixes. Isso, diminui principalmente os peixes que não terão condições ideais de reprodução. No filme os pescadores estavam fazendo protestos.

(pausa)

T11. P: Como que ficam os índios que vivem nesta região onde a água vai diminuir?

T12. P: As tribos provavelmente teriam que mudar de local, diminuindo o peixe vai faltar alimento, neh! Vão ter que procurar outros lugares para viver. 
também seria uma das causas da redução da vazante, em que se constata que os alunos deixaram de assimilar elementos importantes do filme. $\mathrm{O}$ aluno B8 consegue perceber, no incidente da redução da vazante do rio, a possibilidade de desaparecimento de peixes que servem de sustento para indígenas.

As colocações da professora e dos alunos visam representações de fatos relacionadas ao mundo objetivo, são afirmações para constatação de informações acessadas anteriormente. Tanto a professora quanto os alunos se envolvem em formas de argumentação referentes ao discurso teórico. Também, neste momento, por se tratar de uma aula de Ciências, a professora poderia ter explorado o conceito de "vazante".

\subsection{Episódio 2}

Neste episódio, são ampliados os questionamentos para o estabelecimento de discursos prático e teórico, particularmente sobre interpretação de legislação e condições de geração e utilização de energia elétrica.
Na Tabela 3, a seguir, são apresentadas análises de pretensões de validade relativas a alguns dos turnos considerados no Episódio 2.

A professora coloca em discussão a interpretação dada pelos políticos e pelos órgãos públicos em relação ao termo "atingidos", lançando uma pretensão de correção às normas, quando argumenta: "mas no filme mostrou o contrário, os índios serão atingidos". De acordo com a lei, atingidos por barragens são somente as pessoas que têm suas propriedades inundadas; a professora no Turno T2 busca viabilizar a reflexão por parte do aluno desta interpretação da lei. A expressão traz elementos de envolvimento em um discurso prático, o questionamento pela adequação ou correção desta interpretação são situações vivenciadas em âmbito social de regulação nas relações entre sujeitos.

Porém, houve dificuldades relacionadas ao envolvimento dos estudantes em agir comunicativo nesse questionamento sobre interpretação da lei, devido a limitações de compreensão. De acordo com Habermas (2012a), as formas de argumentação cada vez mais rebuscadas e profundas dos especialistas

TABELA 3 - Análise de argumentação. Episódio 2.

\begin{tabular}{ccccc}
\hline Item & Situação & Aspecto em questionamento & $\begin{array}{c}\text { Pretensões de validade } \\
\text { controversas }\end{array}$ & Atitude básica \\
\hline $\mathbf{0 1}$ & Turno T1 & $\begin{array}{c}\text { Interpretação da lei em relação ao } \\
\text { significado de "atingidos" }\end{array}$ & Adequação & Conforme com as normas \\
\hline $\mathbf{0 2}$ & Turno T7 & $\begin{array}{c}\text { Somente a ação de economizar energia } \\
\text { não solucionará o problema que a } \\
\text { construção da usina tem causado aos } \\
\text { indígenas }\end{array}$ & Verdade & Expressiva \\
\hline $\mathbf{0 3}$ & Turno T12 & $\begin{array}{c}\text { Descrédito em relação à economia de } \\
\text { energia pelas pessoas e instituições }\end{array}$ & Sinceridade & Conforme com as normas \\
\hline $\mathbf{0 4}$ & Turno T13 & $\begin{array}{c}\text { Algumas pessoas não agem conforme } \\
\text { combinado no uso de energia }\end{array}$ & Adequação & Expressiva \\
\hline $\mathbf{0 5}$ & Turno T14 & $\begin{array}{c}\text { Relacionado à valorização da vida } \\
\text { humana }\end{array}$ & Sinceridade & \\
\hline
\end{tabular}

FONTE: elaboração própria. 
T1. P: O presidente da FUNAI [Fundação Nacional do Índio] fala no vídeo que os índios não estão sendo atingidos. Atingidos na interpretação dele é somente quem é alagado. Aquelas casas que serão alagadas que pessoas terão que sair, estes são os atingidos. Mas no filme mostrou ao contrário, os índios serão atingidos, mas não com alagamentos e sim diminuindo a água deles. Na sua opinião, qual a solução para isso?

(pausa)

T2. P: No final do vídeo passou notícias sobre apagão, o Brasil está precisando de energia. Qual a solução? O país está precisando de energia. Precisa! Como podemos fazer para resolver isto?

(pausa)

T3. P: Se a hidrelétrica vai atingir indio, vai atingir ribeirinhos, muitas pessoas serão prejudicadas. Qual a solução? Qual sua opinião?

T4. B8: Economizar energia?

T5. P: Economizar energia..., certo. Que mais? Assiiim, a maior parte da energia são as empresas que consomem. De repente só nós economizando energia ainda não vamos resolver o problema.

T6. B8: Diminuir o gasto das empresas.

T7. B2: Se as empresas diminuírem o consumo de energia, talvez melhore.

T8. P: Cada um faz a sua parte para economizar?

T9. B2: Sim

T10. P: Seria fácil fazer isto? Vocês conseguem economizar quando os pais pedem para não demorar no banho, não deixar a luz ligada?

T11. B22: Não professora, fala para economizar, mas só algumas pessoas economizam, eu economizo e os outros não.

T12. P: A B22 colocou aqui, na casa dela ela pode economizar, mas as outras pessoas não economizam.

T13. B22: É muita gente.

T14. P: A pessoa fica no sacrifício.

T15. B2: Este é o problema, não adianta algumas pessoas economizar e outras não.

T16. P: E o governo poderia fazer o que nisto? Nós estamos falando da nossa parte. O governo também tem responsabilidades.

(Pausa)

T17. P: Será que existe só esta forma de produzir energia? Só usinas hidrelétricas?

T18. B22: Solar

T19. B8: Não professora, tem energia solar.

T20. P: A energia solar vai impactar menos as pessoas?

T21. B2: Talvez sim.

T22. P: A energia solar não vai impactar as pessoas, como em uma usina hidrelétrica?

T23. B2: Talvez impactasse, mas o número de pessoas é muito menor.

T24. P: Não seria em alimento?

T25. B2: Também.

T26. P: Por que não se investe em outras formas de energia?

T27. B7: O governo vai gastar mais.

T28. P: É isto, o governo vai gastar mais dinheiro, é uma energia cara, as hidrelétricas são mais baratas.

T29. B2: Em compensação valeria mais a pena a energia solar, ela não tira o alimento das pessoas.

T30. P: B2, então, na sua opinião, não adianta ser uma forma de energia barata e prejudicar as pessoas.

T31. B8: Por que eles não podem gastar mais agora? E a hora que acabar a água? E daí?

(risos da turma)

T32. P: Tá certo, em São Paulo estava faltando água.

T33. B8: Por que não gastar agora?

T34. P: Acontece assim, em épocas de secas as hidrelétricas diminuem a geração de energia, algumas são desligadas porque falta água e nesta época que dá os apagões. 
tornam difícil ou impossibilitam a compreensão das argumentações pela maioria dos indivíduos. Esses problemas se referem ao estabelecimento de discurso explicativo concernente à compreensão de estruturas linguísticas e significados, demandando a necessidade de ampliação do pano de fundo para problematização e construções conjuntas nos âmbitos objetivo, social e subjetivo.

Até este momento, a discussão se encaminhava na intenção de observar os elementos desfavoráveis à construção da usina, mas, no Turno T3, a professora propõe argumentos com o propósito de verificar as impressões dos alunos quanto aos elementos favoráveis à construção da usina. A crise energética experimentada por todos os brasileiros talvez pudesse ser um elemento na discussão capaz de fornecer uma contribuição ao estudante da necessidade, ou não, da construção da usina. No Turno T5, o aluno B8 propõe economizar energia como uma forma de resolver os problemas que a construção da usina tem causado aos indígenas. No Turno T6, a professora lança uma pretensão de verdade: "só nós economizando energia ainda não vamos resolver o problema".

Nos turnos seguintes, os alunos insistiram na economia de energia para a solução do problema; no Turno T11, a professora apresenta uma pretensão de sinceridade de que os estudantes não colocariam em prática a ação sugerida. Logo na sequência, no Turno T12, a aluna B22 responde o questionamento da professora expressando mais uma pretensão de adequação às normas: "eu economizo e os outros não".

Os alunos B2 e B8 propõem que todos devem entrar no sacrifício e diminuir o consumo de energia. A professora questiona a possibilidade de se fazer isso e os alunos B2 e B22 se envolvem em uma situação argumentativa em que são questionadas as atitudes de irresponsabilidade das pessoas em relação ao uso de energia. A aluna B22 questiona o fato de as pessoas não seguirem a recomendação de economizar energia, em exteriorizações que interrogam os aspectos problemáticos relacionados ao campo prático, às regras de uma boa convivência, de uma conduta racional não praticada, em que o compromisso assumido pelas pessoas não se efetiva. São argumentos que se referem à regulação no mundo social e a pretensão de validade controversa se refere à correção das normas de ação.

A partir do Turno T17, a professora procura levar para discussão a responsabilização do Estado em relação à solução dos problemas energéticos e à construção da usina. Já que no campo pessoal os estudantes não conceberam possibilidades de solucionar o problema, questiona-se por investimentos em outras formas de energia que talvez impactassem menos as pessoas, comparadas à hidroeletricidade. No Turno T28, o aluno B7 justifica o fato de o Estado não investir em outras formas energéticas por serem mais caras. Professora e aluno constatam aspectos relacionados ao mundo objetivo; mais do que isso, identifica-se aspecto de invasão do sistema no mundo da vida e percebe-se o dinheiro e o poder político coordenando ações limitadas ao campo estratégico.

Mesmo identificando vários fatores sociais $\mathrm{e}$ ambientais desfavoráveis, Bermann (2007) propõe para o Brasil a hidreletricidade como alternativa de geração de energia. De acordo com o autor, há necessidade de reconhecer e considerar os danos sociais e ambientais e conduzir a situação de uma forma justa e sustentável. Ele também aponta possíveis soluções para mitigar esses impactos, entre os quais, a potencialização das usinas já existentes e a construção de pequenas usinas hidrelétricas.

No Turno T30, ao constatar a invasão do sistema no mundo da vida, o aluno B2 argumenta colocando uma pretensão de sinceridade, o apreço pela vida do ser humano, envolvendo aspectos do âmbito subjetivo, integrantes de sua personalidade. 


\subsection{Episódio 3}

Neste episódio, destaca-se a ampliação do discurso prático, concernente à constituição de normas e direitos.

Na Tabela 4, a seguir, são apresentadas análises de pretensões de validade relativas a alguns dos turnos considerados no Episódio 3.

No início do episódio, Turno T1, a professora traz para a discussão a forma como o político se expressa em relação à construção da usina; para o político, esta controvérsia já foi decidida pelo Congresso Nacional e não existe mais nada que possa ser feito. Neste turno, a professora traz elementos pertencentes ao âmbito social e a argumentação tematiza um conflito a ser resolvido de acordo com as leis, pois, para o político em questão, as discussões e anseios da população atingida em relação à construção da usina podem ser desconsiderados. Pressupõe-se que as normas de ação que regem esta controvérsia expressam um interesse comum, as expressões da professora colocam em questão se a decisão final está adequada ou necessita ser corrigida.

No Turno T2, a aluna B19 traz para o debate elementos pertencentes ao âmbito subjetivo, uma exteriorização de sentimentos, desejos e atitudes, uma crítica quanto aos aspectos de sinceridade. Na sequência, Turno T3, a professora explicita questionamentos relacionados ao desempenho e

TABELA 4 - Análise de argumentação. Episódio 3.

\begin{tabular}{lllll}
\hline Item & Situação & Aspecto em questionamento & $\begin{array}{l}\text { Pretensões de validade } \\
\text { controversas }\end{array}$ & Atitude básica \\
\hline $\mathbf{0 1}$ & Turno T1 & $\begin{array}{l}\text { A lei afirma que o Congresso Nacional deve } \\
\text { tomar a decisão final em relação à construção } \\
\text { da usina }\end{array}$ & Adequação & Conforme com as normas \\
\hline $\mathbf{0 2}$ & Turno T2 & Falta de lisura nas decisões políticas & Sinceridade & Atitude expressiva \\
\hline $\mathbf{0 3}$ & Turno T3 & $\begin{array}{l}\text { Atitude de mudança em relação ao desempe- } \\
\text { nho e conduta na pessoa do político }\end{array}$ & Acerto & Conforme com as normas \\
\hline
\end{tabular}

FONTE: Elaboração própria.

T1. P: Táh! Aquele político, "Nicias" é o nome dele, não dizia o cargo, disse numa entrevista no documentário "não adianta vir movimento ambiental, não adianta vir OEA, que está decidido, já foi decidido, a usina vai sair, quem que manda no Brasil? É o Congresso Nacional, o Congresso Nacional decidiu, pronto, acabou, a usina vai ser construída. Não tem movimento, não adianta os índios se pintarem de vermelho, está decidido".

T2. B19: Para ele está decidido, porque não vai ser ele que vai ser prejudicado pela falta de peixe. Ele deveria pensar mais nas pessoas, só pensou nele. Tipo, eles falam nós vamos construir, será que eles pensaram nas pessoas que serão prejudicadas nisto tudo? Não pensaram.

T3. P: O que faz um político, por exemplo, a gente elege pensando assim, vai me representar, vai defender os meus interesses, dai chega lá e faz tudo ao contrário do que o povo quer. Qual a forma da gente resolver esta situação? (pausa)

T4. P: A gente acredita, dá o voto de confiança. Daí chega lá o político só defende seus próprios interesses.

T5. B22: Na hora da eleição faz bastante promessa, neh professora!

(pausa) 
à conduta de políticos, que são eleitos de acordo com as normas para representar e defender os interesses da população, mas acabam não cumprindo compromissos assumidos com os eleitores. No Turno T5, a aluna B22 se manifesta corroborando o entendimento da professora.

De acordo com Bermann (2007), uma participação efetiva das populações atingidas pelas usinas hidrelétricas, no processo de decisão em relação à obra, constitui um desafio, com a existência de impedimentos difíceis de superar. Para Vainer (2007), o que menos se discute no Congresso Nacional são os interesses e projetos nacionais. Para este autor, temáticas envolvendo energia e meio ambiente, impactos sociais e ambientais das políticas energéticas são decididas por um pequeno grupo de pessoas, com interesses políticos e econômicos específicos. Não existe um debate público aberto.

Habermas (2012b) constata que, no processo de colonização do mundo da vida, o capitalismo avançado tem obtido sucesso em neutralizar, cada vez mais, a esfera pública como espaço de participação efetiva dos cidadãos. A sociedade se torna duplamente dependente do sistema, pela transferência do seu poder decisório como cidadão para a instância burocrática do Estado e pela quase inteira submissão aos ditames do consumo. Com uma imposição legal do Estado, a esfera da vida privada perde sua força de orientação, gerando problemas de legitimação. O dever ético do político passa a ser substituído por atitudes instrumentais; a ação política é indiferente a valores éticos e compromissos sociais. Isso tem como consequência o surgimento de patologias como a perda da liberdade, a perda de sentido e o empobrecimento cultural, as quais ameaçam o mundo da vida (Mühl, 2003).

\subsection{Episodio 4}

Neste episódio, podem ser destacados os discursos teórico e prático, com alusão a aspectos do âmbito subjetivo.

Na Tabela 5, a seguir, são apresentadas análises de pretensões de validade relativas a alguns dos turnos considerados no Episódio 4.

No Turno T1, a professora retoma elementos do filme que informam que 4.000 pessoas serão desalojadas, mas lança uma pretensão de verdade envolvendo um político que defende a construção da usina. Segundo este político, estas pessoas seriam beneficiadas e não desalojadas.

Nos Turnos T2 a T4, os alunos lançam outras pretensões de verdade, agora em relação aos procedimentos de remoção dos atingidos, pois inferiram no filme que a mudança para as novas casas poderia não acontecer. No Turno T5, a professora traz elementos do âmbito objetivo para corroborar as pretensões lançadas pelos alunos.

TABELA 5 - Análise de argumentação. Episódio 4.

\begin{tabular}{ccccc}
\hline Item & Situação & Aspecto em questionamento & $\begin{array}{c}\text { Pretensões de validade } \\
\text { controversas }\end{array}$ & Atitude básica \\
\hline $\mathbf{0 1}$ & Turno T1 & $\begin{array}{c}\text { Desalojamento das pessoas atingidas } \\
\text { pela inundação }\end{array}$ & Verdade & Objetiva \\
\hline $\mathbf{0 2}$ & Turno T2 & $\begin{array}{c}\text { Credibilidade na ação de remoção dos } \\
\text { atingidos }\end{array}$ & Verdade/Veracidade & Objetiva/Expressiva \\
\hline
\end{tabular}

FONTE: Elaboração própria. 
T1. Professora: tem uma parte do vídeo que fala que 4.000 pessoas serão desalojadas, mas um político diz que elas não serão desalojadas, mas sim beneficiadas, porque elas irão sair das palafitas, lá do meio da água e irão para casas de alvenaria, higiênicas, por este lado, aquelas pessoas que moram lá perto do rio lá....

T2. B16: Elas não acreditam que isso vá acontecer.

T3. B2: Éh! Eles falaram que não acreditam.

T4. B16: Eles acham que vão tirar da casa deles e vão deixar eles abandonados.

T5. P: Éh, eles não haviam dito aonde seriam construídas as casas. Teve uma senhora que disse "só passam aqui e perguntam qual teu nome, qual teu nome".

T6. P: E aquela mulher que falou "será que lá onde eu for vai ter roupa para eu lavar? Porque eu vivo de lavar roupa".

T7. B22: Tirar eles de uma realidade e levar para outra realidade é complicado.

T8. P: Lembram do agricultor, dos pés de cacau, lembram?

T9. B19: Ele disse que era o meio de sobrevivência dele.

T10. P: Ele ia sair de lá onde ele estava, a chácara dele ia ser alagada, ele ia para onde? Para estas casas de alvenaria, higiênicas, como que ele ia viver, que ele ia fazer? Não é só pegar e tirar a pessoa, não é só casa dele ali, tem o meio de sobrevivência. O agricultor da chácara que iria inundar ganharia uma casa na cidade. Eles teriam que dar outro meio de sobrevivência. Teve um agricultor que falou que era analfabeto, como iria para a cidade? Não é só isso, as palafitas são feias, estão no meio da água, as pessoas irão para casas mais bonitas, isto é o suficiente?

T11. B2: O que ele vai comer, do que ele vai viver, como ele vai sustentar a própria casa dele?

T12. P: A partir dai vem o problema.

Os atingidos pela inundação são obrigados a mudar de forma drástica seu modo de vida, o que poderia resultar em perda de identidade. De acordo com Habermas (1968), o controle técnico das demandas sociais isola os interesses e as necessidades coletivas; tal estratégia faz com que as necessidades e os interesses não sejam percebidos como extensivos a todos e identificados como demandas sociais, uma renovada forma de dominação alienante.

De acordo com Bermann (2007), ignorar os problemas sociais e ambientais e as populações atingidas pelos empreendimentos hidrelétricos para diminuir custos e não reconhecer grupos sociais historicamente formados em determinada região diminui, no domínio político, possibilidades de negociação. No processo de tomada de decisão sobre a instalação de projetos hidrelétricos, existem entraves que impedem a participação dos interessa- dos, o envolvimento da sociedade nestas questões é limitado e as determinações chegam, principalmente, para serem cumpridas por esses sujeitos.

\section{Considerações finais}

Nos episódios apresentados, foi possível observar a articulação entre os discursos teórico e prático, em que se relacionavam questionamentos/ explicitações de concepções, saberes e conhecimentos estabilizados com processos e interesses envolvidos na constituição de normas e direitos. Sob o âmbito social, houve a ampliação do escopo de um documento de legislação para a ação de políticos e as populações envolvidas no processo. Nesses episódios perpassaram, também, aspectos do âmbito subjetivo. Isto representa uma compreensão de educação em ciências para além do 
discurso explicativo, viabilizando aos sujeitos do processo educacional o envolvimento em situações de problematização e proposições de alternativas para construções conjuntas.

Entretanto, observou-se nos episódios de fala que o envolvimento argumentativo em sala de aula precisa ser ampliado. No decorrer do processo comunicativo, os alunos respondem questionamentos lançados pela professora e em alguns momentos se calam diante das indagações da docente. Envolvimento em processo dialógico em sala de aula tem sido prática pouco realizada e, nos momentos em que se fazem investimentos nessa forma de trabalho educativo, muitas vezes professor e alunos apresentam dificuldades. Mesmo o professor tendo se preparado para tal momento, existe uma inquietação, pois não consegue prever o direcionamento desse processo educativo.

Também se constatou que poderia ser ampliada a abordagem de conceitos científicos; essa constatação representa limitações no discurso explicativo. Demonstra-se, nessa situação, difi-

\section{Referências}

Bardin, L. Análise de conteúdo. São Paulo: Edições 70, 2011.

Belo Monte, o anúncio de uma guerra. Direção: André D'Elia. Produção: Beatriz Vilela e Francisco D'Elia. São Paulo: Cinedelia, 2012. Duração 104 min. Disponível em: $<$ https://vimeo.com/cinedelia>. Acesso em: 27 abr. 2016.

Bermann, C. Impasses e controvérsias da hidreletricidade. Estudos Avançados, 21(59), 139-153, 2007. Disponível em: <http://www.scielo.br/pdf/ea/v21n59/a10v2159.pdf>

Delizoicov, D.; Angotti, J. A. P.; Pernambuco, M. M. C. A. Ensino de ciências: fundamentos e métodos. São Paulo: Cortez, 2002. culdade no trabalho pedagógico para se trabalhar o conhecimento científico em temáticas sociais às quais estão vinculados. Mas, apesar das dificuldades encontradas no processo educativo, destacam-se possibilidades de apropriação do conhecimento científico, principalmente nas proposições de alternativas, nas sugestões de formas para solucionar problemas.

Os alunos foram apresentados às temáticas que possibilitaram a formação de uma visão social e política voltada ao combate às patologias do sistema. $\mathrm{O}$ envolvimento dos alunos em processo dialógico em temas controversos aponta possibilidades de formação para o entendimento e acordo.

Apesar das dificuldades do processo pedagógico analisado e da reduzida participação dos alunos no processo comunicativo, ressalta-se o desafio aos educadores de que estes precisam se tornar "críticos permanentes e incansáveis do processo conflituoso, contraditório, contingente que é a educação, a qual necessita, por causa dessa sua natureza, de uma permanente revalidação" (Mühl, 2003, p. 264).

Ferreira, D. T. A. M.; Marques, E. E.; Buenafuente, S. M. F.; Souza, L. B.; Grison, M. G.; Lima, A. M. T. de. Perdas simbólicas e os atingidos por barragens: o caso da Usina Hidrelétrica de Estreito, Brasil. Desenvolvimento e Meio Ambiente, 30, 73-87, 2014. Disponível em: $<$ http://ojs.c3sl. ufpr.br/ojs2/index.php/made/article/view/34187/22870>

Flick, U. Introdução à pesquisa qualitativa. 3. ed. Porto Alegre: Artmed, 2009.

Freire, P. Pedagogia do oprimido. 17. ed. Rio de Janeiro: Paz e Terra, 1987.

Habermas, J. Técnica e ciência como ideologia. Lisboa: Edições 70, 1968. 
Habermas, J. Racionalidade e comunicação. Lisboa: Edições 70, 2002.

Habermas, J. Teoria do agir comunicativo I: racionalidade da ação e racionalização social. São Paulo: WMF Martins Fontes, 2012a.

Habermas, J. Teoria do agir comunicativo II: sobre a crítica da razão funcionalista. São Paulo: WMF Martins Fontes, 2012b.

Morin, E. Os sete saberes necessários à educação do futuro. 2. ed. São Paulo: Cortez, 2000.

Mühl, E H. Habermas: ação pedagógica como agir comunicativo. Passo Fundo: UPF, 2003.

Ratcliffe, M.; Grace, M. Science Education for Citizenship: teaching socio-scientific issues. Philadelphia: Open University Press, 2003.
Rezende, L. P. Dano moral e licenciamento ambiental de barragens hidrelétricas. Curitiba: Juruá, 2002.

Vainer, C. B. Recursos hidráulicos: questões sociais e ambientais. Estudos Avançados, 21(59), 119-137, 2007. Disponível em: <http://www.scielo.br/pdf/ea/v21n59/ a09v2159.pdf>

Van Eemeren, F. H.; Grootendorst, R. A systematic theory of argumentation: the pragma-dialectical approach. Cambridge: Cambridge University Press, 2004.

Zoller, U. The Technology/Education Interface: STES Education for All. Canadian Journal of Education, 17(1), 86-91, 1992. Disponível em: <http://www.csse-scee.ca/ CJE/Articles/FullText/CJE17-1/CJE17-1-07Zoller.pdf>. 